\title{
On the optimum operating temperature for steam floods
}

\author{
Kazeem A. Lawal ${ }^{1}$ (D) . Olugbenga Olamigoke ${ }^{2}$
}

Received: 28 July 2020 / Accepted: 24 December 2020 / Published online: 6 January 2021

(C) The Author(s) 2021 OPEN

\begin{abstract}
The technical, environmental and economic performances of a steam flood are partly influenced by the operating temperature (pressure). However, the definition and procedure for determining the optimum operating temperature are still debatable. Employing a combination of analytic modelling and numerical simulations, this paper investigates the existence (or otherwise) of an optimum injection temperature $T_{\text {opt }}$ for saturated-steam floods. Considering the maximization of productivity and thermal efficiency as objective, an analytic procedure, which explores the effects of temperature on injectivity, total steam enthalpy, oil viscosity and relative permeabilities, shows that the operating temperature (pressure) of a steam flood should not exceed $515 \mathrm{~K}$ (3.5 MPa). A simple closed-form expression is proposed for $T_{\text {opt }}$ as a function of basic rock and fluid properties. For an example three-dimensional reservoir model comprising an 8-m oil shale unit sandwiched between two sandy units each $15 \mathrm{~m}$ thick, numerical simulations show sensitivity to temperature (and viscosity effect) in the range 350-450 K, but becomes increasingly insensitive in the band $500-650 \mathrm{~K}$. It is established that $\sim 500-550 \mathrm{~K}$ is the optimum band when the optimization objective is to maximize both discounted oil recovery and cumulative oil-steam ratio. These results agree with an optimum injection temperature of $\sim 501 \mathrm{~K}$ estimated from the proposed analytical model in this case. Therefore, based on the results of the analytical model, thermal simulations and other considerations, it is concluded that the optimum steam-injection temperature is project and system specific. The insights gained should find relevance in the design and management of steam floods, as well as other steam-based recovery processes.
\end{abstract}

Keywords Steam flood·SAGD $\cdot$ Injection temperature $\cdot$ Injection pressure $\cdot$ Thermal simulations $\cdot$ Bitumen

\section{Introduction}

A combination of increasing oil demand and declining supply from conventional sources continues to fuel the interests of energy developers in unconventional oil resources such as natural bitumen. Apart from their occurrence in vast quantities [1,2], a common feature of these resources is that they are characterized by relatively high viscosities and largely immobile under reservoir conditions. As a result, they are typically associated with subeconomic natural production rates $[3,4]$.
Owing to the ready availability of water and the high heat-carrying capacity of steam, water remains a preferred thermal agent, explaining why steam-based processes are the most popular for the in-situ development of these vast resources [5, 6]. In principle, the injected heat raises the reservoir temperature, reducing in-situ oil viscosity, thus improving oil mobility and productivity. Obviously, the net heat available to the reservoir, the attainable viscosity reduction and upgrading of the in-situ oil are functions of the operating injection temperature and pressure [7].

The intensity of $\mathrm{CO}_{2}$ emissions, non-productive thermal losses as well as fuel and other operating costs of a steam

$\varangle$ Kazeem A. Lawal, kazeem.lawal@first-epdc.com; Olugbenga Olamigoke, oolamigoke@unilag.edu.ng | ${ }^{1}$ FIRST Exploration and Petroleum Development Company (FIRST E\&P), Lagos, Nigeria. ${ }^{2}$ Department of Chemical and Petroleum Engineering, University of Lagos, Lagos, Nigeria. 
flood can partly be related to the steaming temperature $[3,4,8]$. Therefore, to improve the recovery, thermal and environmental efficiencies as well as the economics of a steam-based development projects, it is imperative to define and implement the optimum steam injection temperature (pressure).

From the standpoints of operational integrity as well as safety and environmental performances, shallow heavyoil and bituminous reservoirs are particularly vulnerable to high-pressure steam injection. Such reservoirs, which typically have limited or no cap rock, are not uncommon [9-11]. Based on thermal reservoir simulations, Al-Turki et al. [9] emphasized the criticality of pressure control when employing steam-based processes to exploit this class of reservoirs.

Leveraging on technical and practical evidence, Edmunds and Chhina [12] investigated the most economical optimum operating pressure for steam-assisted gravity drainage (SAGD) projects in northeast Alberta, Canada. They recommended a general economic optimum pressure range of $0.3-0.9 \mathrm{MPa}$ (407-448 K) for SAGD projects.

In a later study, Nguyen et al. [13] confirmed that SAGD efficiency was controlled by both reservoir properties and operating conditions. Specifically, applying D-optimal design and response surface methodology while focusing on the maximization of net-present value as the objective function, they investigated the impacts of several operating variables, which included preheating, injector/ producer spacing, steam injection pressure and rate. They concluded that $5 \mathrm{MPa}(537 \mathrm{~K})$ was the optimum steam injection pressure (temperature) for SAGD in Athabasca, Canada. It is noteworthy that their conclusion was at variance with that of Edmunds and Chhina [12].

Contrary to views supporting low-temperature (pressure) injection [12], Collins [14, 15] argued in favor of high-temperature operations. Although low-temperature minimizes the amount of heat injected, high-temperature minimizes the net amount of heat injected because more heat is recoverable from the produced fluids and retained in the formation. As noted by Collins [15], the beneficial effects of geomechanics are more pronounced at high temperatures (pressures). However, for a balanced view, one must be mindful of the interplay between latent and sensible heats of steam versus temperature. As the critical temperature is approached, latent heat decreases dramatically, making high-temperature steaming less optimal. Hence, for every scenario, one would expect some optimum operating temperature.

In searching for the optimum steam temperature to heat a bitumen-bearing reservoir, some workers focused on the viscosity-versus-temperature characteristics of the bitumen in question [16]. As a guide, he suggested that the optimum temperature is that at which the viscosity-versus-temperature curve goes asymptotic. This asymptotic temperature was found by taking successive gradients of the viscosity-temperature curve and establishing the temperature at which the change in gradient starts becoming negligible between successive temperatures. An obvious deduction from this technique is that the optimum temperature is fluid specific, hence should be evaluated on a case-by-case basis. Another shortcoming of this technique is the impression that the reduction of oil viscosity is the only determinant of the optimum operating temperature (pressure), downplaying the effects of other factors such as rock properties, steam flow behavior, completion type and thermal efficiency $[3-5,13,17]$.

O'Dell [18] investigated the optimum steam zone pressure in steam flood projects. The author noted the detrimental effect of a low steam-zone pressure (temperature) on oil production rates, as it implies lower drawdown and limited viscosity reduction. Conversely, it was observed that operating costs reduce with lower steam pressure. Based on this work, the competing interplay of productivity and operating costs suggests the existence of an economic optimum steaming pressure and temperature. However, it is instructive that the author did not conclude on a universal optimum point but recommended that a cost-benefit analysis should always be conducted for any steam flood project.

Using artificial neural network, Kam et al. [19] studied the optimal strategy to establish the operating pressures (temperatures) that would maximize the economic value of solvent-aided thermal recovery projects. The objective function was set up as a multi-variable problem, with the optimization variables including bitumen production, steam injection, solvent retention and oil price. However, application of their work to Athabasca oil sands did not reveal the existence of an optimum operating pressure, but rather proposed an optimal schedule of different operating pressures.

Recently, Tian et al. [6] published their findings from a set of three-dimensional (3D) laboratory experiments on SAGD feasibility in high-pressure environments. Considering oil recovery factor, cumulative oil-steam-ratio and the quality of produced oil as key performance indicators, they concluded that SAGD was not feasible in high-pressure environments. They recommended that overpressured heavy-oil reservoirs should be depressurized prior to executing a SAGD process.

In this paper, we investigate the optimum injection temperature for steam floods. Taking advantage of fundamental principles and considering multiple factors, we interrogate the existence (or otherwise) of an optimum steaming temperature. From these theoretical investigations, a simple analytical model is proposed for estimating optimum temperature for saturated steam floods. Afterward, the robustness 
of this model is examined using 3D, multiphase numerical simulations of a SAGD process.

We are not unaware of recent efforts to achieve dramatic improvement in the recovery efficiency of steam floods by injecting supercritical steam (i.e. above $647.5 \mathrm{~K}$ and $22.1 \mathrm{MPa}$ ) for the exploitation of heavy oil and bitumenbearing reservoirs $[7,20]$. However, to keep the problem tractable and limited to the main recovery mechanisms of viscosity reduction and alteration of relative permeabilities, this paper focuses on traditional steam floods, in which sub-critical steam is utilized. This notwithstanding, where supercritical temperature $(650 \mathrm{~K})$ is considered, this study ignores complex recovery mechanisms such as solvent action, decoking and pyrolysis, that have been linked to such conditions [7, 21].

This paper is organized into three major sections. The theoretical framework and formulation of analytical models are presented. This is followed by discussions on the parametric tests conducted on the new analytical model and the results obtained. Insights from model validations with numerical thermal simulations are discussed. The final section presents the key conclusions and limitations of this work, while offering future directions for research that could advance the current body of knowledge on this subject.

\section{Theoretical framework}

In this section, we examine some rock and fluid properties that are known to influence the performance of a steam flood. Leveraging on the temperature-dependency of such properties, we seek a functional relationship between a given performance indicator and the specific rock and fluid property of interest. The same concept of analyzing the temperature dependency is extended to the total steam enthalpy, which influences the thermal efficiency of a steam flood.

Effect of oil viscosity only: In this case, we consider the basic principle of a thermal flood, which is to accomplish significant reduction of in-situ oil viscosity by elevating the temperature. Accordingly, we explore the functional relationship between oil viscosity and temperature to find a possible optimum steam injection (operating) temperature.

Considering the common two-parameter Andrade viscosity model, oil dynamic viscosity and temperature are related as follows [22].

$\mu_{o}=\mu_{o i} e^{a / T}$,

where $\mu_{\mathrm{oi}}$ and $a$ are empirical constants measured in Pa.s and $K$, respectively. $T$ is absolute temperature $(K) . \mu_{o}$ is the dynamic viscosity (Pa.s) at the prevailing temperature $T$.

In seeking the optimum injection temperature from the standpoint of oil viscosity only, we are looking for that injection temperature that always minimizes oil viscosity in the reservoir. Mathematically, this search requires setting the temperature derivative of Eq. 1 to zero and solving for $T$ i.e.

$\frac{d \mu_{o}}{d T}=-\frac{a \mu_{\text {oil }}}{T^{2}} e^{a / T}=0$.

Solving Eq. 2 yields the solution $T=\infty$. This result suggests the non-existence of a unique and physically realistic temperature that guarantees minimum in-situ oil viscosity. Therefore, from the viewpoint of oil-viscosity effect only, it does not appear that there is a realistic optimum injection temperature for steam floods.

Effect of steam injectivity only: This approach considers the impact of temperature on steam injectivity. Given the simple case of a radial incompressible two-phase flow in a porous medium, the injectivity of steam at steady-state conditions is expressed as follows.

$$
J_{s}=\frac{2 \pi k k_{r s} h}{B_{s} \mu_{s}\left(\log _{e} \frac{R_{e}}{r_{w}}+s\right)},
$$

in which $J_{s}=$ steam injectivity index $\left(\mathrm{m}^{3} \mathrm{~s}^{-1} \mathrm{~Pa}^{-1}\right), k=$ absolute permeability $\left(\mathrm{m}^{2}\right), k_{r s}=$ steam relative permeability (dimensionless), $h=$ formation thickness $(\mathrm{m}), \mu_{\mathrm{s}}=$ steam viscosity (Pa s), $B_{s}=$ steam volume factor (dimensionless), $R_{e}=$ reservoir radius $(\mathrm{m}), r_{w}=$ wellbore radius $(\mathrm{m})$, and $s=$ skin factor (dimensionless).

To simplify our search for an optimum temperature from a steam-injectivity viewpoint, we assume that only the quantity $\mu_{s}$ is temperature-dependent in Eq. 3. As a result, we use the following correlation of Tortike and Farouq-Ali [23] to describe saturated steam viscosity ( $\mathrm{Pa}$ s) versus temperature $(K)$. This correlation is valid within the range $273.15 \leq T \leq 645 \mathrm{~K}$.

$\mu_{s}=-5.46807 \times 10^{-4}+6.8949 \times 10^{-6} T-3.35009 \times 10^{-8} T^{2}+8.29842 \times 10^{-11} T^{3}$

$-9.9706 \times 10^{-14} T^{4}+4.71914 \times 10^{-17} T^{5}$

Following the application of chain rule to Eqs. 3 and 4 i.e. $\frac{d J_{s}}{d T}=\frac{d J_{s}}{d \mu_{s}} \cdot \frac{d \mu_{s}}{d T}$, and setting $\frac{d J_{s}}{d T}=0$, to search for the optimum temprature, we obtain the following equation.

$$
\begin{aligned}
6.8949 \times 10^{-6}- & 6.70018 \times 10^{-8} \mathrm{~T}+2.48953 \times 10^{-10} T^{2} \\
& -3.98824 \times 10^{-13} T^{3}+2.35957 \times 10^{-16} T^{4}=0 .
\end{aligned}
$$

Again, solving Eq. 5 does not yield a unique and physically realistic temperature as the optimum. Therefore, from the standpoint of steam injectivity, there is no unique optimum temperature.

Effect of total steam enthalpy: By summing expressions for specific latent and sensible enthalpies, the specific total enthalpy (in $\mathrm{kg}^{-1}$ ) of a saturated steam in 
the temperature range $273.15 \leq T \leq 645 \mathrm{~K}$, is given by the following correlation [23]. porous medium, the productivity of oil at steady-state conditions is expressed as follows.

$$
\begin{aligned}
E= & 1000\left(7184500+11048.6 T-88.4050 T^{2}+0.162561 T^{3}-1.21377 \times 10^{-4} T^{4}\right)^{1 / 2} \\
& +1000\left(\begin{array}{l}
23665.2-366.232 T+2.26952 T^{2}-0.00730365 T^{3}+1.30241 \times 10^{-5} T^{4} \\
-1.22103 \times 10^{-8} T^{5}+4.70878 \times 10^{-12} T^{6}
\end{array}\right) .
\end{aligned}
$$

In the search for a temperature that optimizes the total enthalpy carried by the injected steam, we derive the equation $d E / d T=0$ and solve same for $T$. Fig. 1 displays the resulting $d E / d T$ vs. temperature curve for saturated steam. From this plot, it is deduced that $\sim 515 \mathrm{~K}$ is the temperature that yields the optimum specific total enthalpy of injected steam. Therefore, strictly from the standpoint of thermal efficiency, it can be concluded that the operating temperature (pressure) of a steam flood should not exceed $515 \mathrm{~K}$ (3.5 MPa). At higher temperatures, there is an increasing risk of operating a suboptimal steam flood, whose thermal efficiency may not be competitive. This increased risk can be attributed to two effects vis-à-vis (i) lower injected total enthalpy at higher temperatures, and (ii) higher thermal losses due to larger temperature difference between injected steam and the surroundings, including along surface injection and production networks, wellbores and adjacent formations $[18,24,25]$.

Combined effects of oil viscosity and relative permeability: In this case, we examine the impacts of temperature on oil productivity (mobility), as influenced by both in-situ viscosity and relative permeability. Given the simple case of a radial incompressible two-phase flow in a

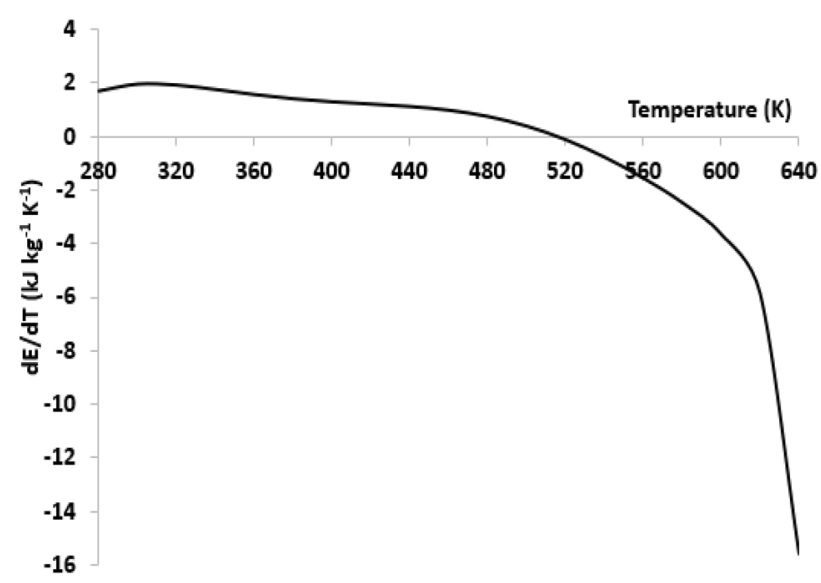

Fig. $1 d E / d T$ vs. temperature plot for saturated steam, suggesting that the heat-carrying capacity of a steam flood becomes sub-optimal above $515 \mathrm{~K}(3.5 \mathrm{MPa})$

\section{SN Applied Sciences}

$$
J_{o}=\frac{2 \pi k k_{r o} h}{B_{o} \mu_{o}\left(\log _{e} \frac{R_{e}}{r_{w}}+s\right)},
$$

where $J_{o}=$ oil productivity index $\left(\mathrm{m}^{3} \mathrm{~s}^{-1} \mathrm{~Pa}^{-1}\right), k_{\mathrm{ro}}=$ oil relative permeability (dimensionless), and $B_{o}=$ oil volume factor (dimensionless).

For convenience, we restrict the current treatment of temperature effects on $J_{0}$ to the examination of the mobility terms $k_{r o}$ and $\mu_{o}$ only. The temperature-derivative of $J_{o}$ requires applying the following chain rule to Eq. 7 .

$\frac{d J_{o}}{d T}=\frac{\partial J_{o}}{\partial k_{r o}} \frac{d k_{r o}}{d T}+\frac{\partial J_{o}}{\partial \mu_{o}} \frac{d \mu_{o}}{d T}$.

While the resolution of the second terms on the righthand side of Eq. 8 are straight-forward, the quantity $d k_{\text {ro/ }} d T$ in the first term is more demanding.

For mathematical convenience, we assume an arbitrary relative-permeability model for a two-phase oil-water system.

$k_{r o}=k_{r o m}\left(\frac{1-S_{w}}{1-S_{i w}}\right)^{n_{o}}$,

in which $k_{\text {rom }}=$ end-point oil relative permeability at connate water saturation (dimensionless), $S_{w}=$ water saturation (dimensionless), $S_{i w}=$ irreducible-water saturation (dimensionless), and $n_{o}=$ oil relative-permeability exponent (dimensionless). Note that the quantities $k_{r o}, k_{\text {rom }}, S_{w}$ and $S_{i w}$ are physically bounded to the range $0-1$.Based on the efforts of different generations of researchers, the sensitivities of relative permeability to temperature have been established for both sandstone and carbonate formations [26-28]. More important, though to varied degrees, several researchers reported and applied temperature effects on the end-point saturations (either residual oil or connate water), hence oil relative permeability [26-29].

Based on the foregoing experimental and theoretical studies, we employ the following semi-empirical relationship between $S_{i w}$ and temperature [28]. By deductive argument, the same expression can readily be used to derive a model of $k_{r o}$ vs. temperature, which is our current interest (see Eq. 8). 
$S_{i w}=\alpha T+\beta$,

in which the quantities $\alpha$ and $\beta$ are empirical constants. They are measured in $\mathrm{K}^{-1}$ and dimensionless units, respectively.

Considering Eqs. 9 and 10 while assuming that $k_{\text {rom }} n_{o}$ and $S_{w}$ are not sensitive to temperature changes, we apply the following chain rule. It is worthy of note that the validity of $\partial S_{w / \partial T}=0$ has been demonstrated by Nakornthap and Evans [28].

$\frac{d k_{r o}}{d T}=\frac{d k_{r o}}{d S_{i w}} \frac{d S_{i w}}{d T}$.

Combining Eqs. 1, 7 and 9-11, then substiting in Eq. 8 yields the temperature-derivative of $J_{0}$. Setting this derivative to zero, we have

$\alpha n_{o} T^{2}-a \alpha T+a(1-\beta)=0$.

Solving Eq. 12 for $T$ yields the following expression for the optimum injection (operating) temperature (in K) which, in principle, maximizes oil productivity under the synergistic effects of reduced oil viscosity and increased oil relative permeability.

$T_{\text {opt }}=\frac{a \alpha \pm \sqrt{a^{2} \alpha^{2}-4 a \alpha n_{o}(1-\beta)}}{2 \alpha n_{o}}, \alpha n_{o} \neq 0$.

For practical applications, the realistic values from Eq. 13 should be limited to the range $273.15 \leq T_{\text {opt }} \leq 645 \mathrm{~K}$. This is the practical range of temperature of a saturated steam.

To ensure that Eq. 13 always returns real solutions for $T_{\text {opt }}$, we impose additional constraints on the discriminant i.e.

$\left[a^{2} \alpha^{2}-4 a \alpha n_{o}(1-\beta)\right] \geq 0$, else we set $\left[a^{2} \alpha^{2}-4 a \alpha n_{o}(1-\beta)\right]=0$.

\section{Results and discussion}

\subsection{Parametric tests}

For the purpose of illustration, Figs. 2, 3, 4 and 5 show the results of some parametric tests conducted with Eq. 13 . From these plots, the optimum temperature is seen to be a function of the rock and fluid properties. It is worthy of note that these results suggest that the optimum temperature depends on the characteristics of the system in question. This deduction is in contrast with the conclusions of some workers $[12,13]$, who recommended $537 \mathrm{~K}$ (5 MPa) and 407-448 $\mathrm{K}(0.3-0.9 \mathrm{MPa})$, respectively as the

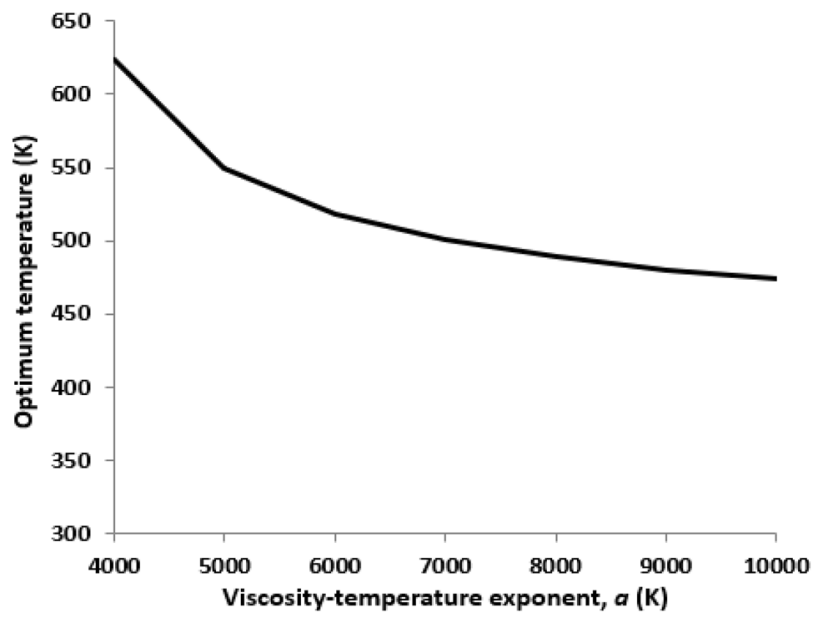

Fig. 2 Optimum operating temperature to maximize oil productivity and recovery as a function of the temperature-sensitivity of insitu oil for an example steam flood $\left(\alpha=0.002455 \mathrm{~K}^{-1}, \beta=-0.05325\right.$ and $n_{o}=2.0$ )

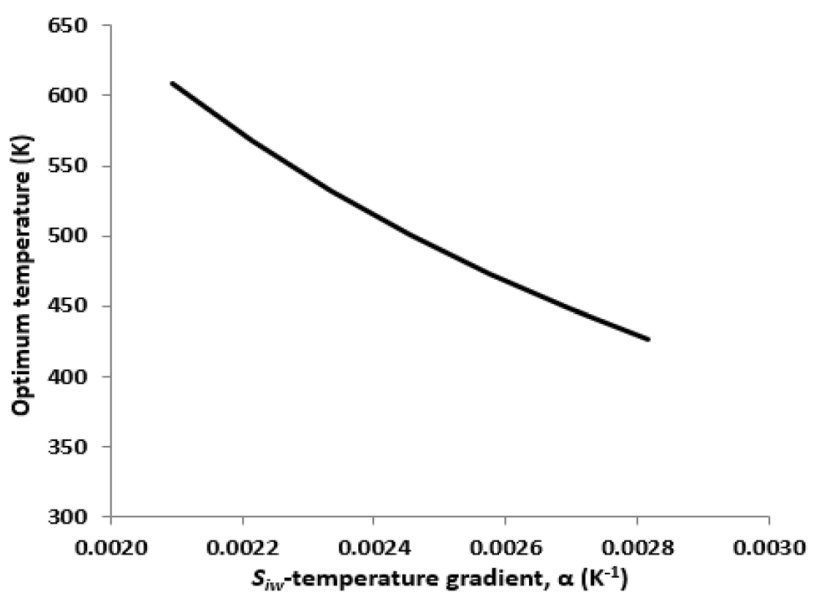

Fig. 3 Optimum operating temperature to maximize oil productivity and recovery as a function of the temperature-sensitivity of irreducible water saturation for an example steam flood $(a=7000 \mathrm{~K}$, $\beta=-0.05325$ and $n_{o}=2.0$ )

general optimum operating conditions for steam-flooding projects.

\subsection{Model validation}

A 3-D semi-homogeneous multiphase reservoir model is constructed with STARS, which is a commercial thermal simulator developed by the Computer Modelling Group. STARS is a standard industry software for numerical modelling of enhanced recovery processes involving displacing with fluid systems such as steam, air, solvents or chemicals. To evaluate the robustness of our proposed analytical model (Eq. 13), we employed the 3D numerical 


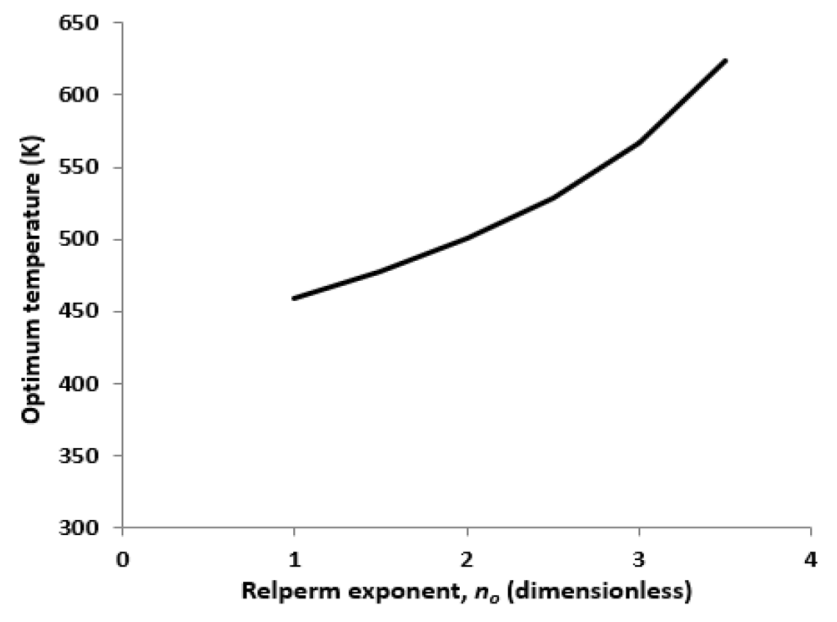

Fig. 4 Optimum operating temperature to maximize oil productivity and recovery as a function of oil relative-permeability exponent for an example steam flood $\left(a=0.002455 \mathrm{~K}^{-1}, a=7000 \mathrm{~K}\right.$ and $\beta=-0.05325$ )

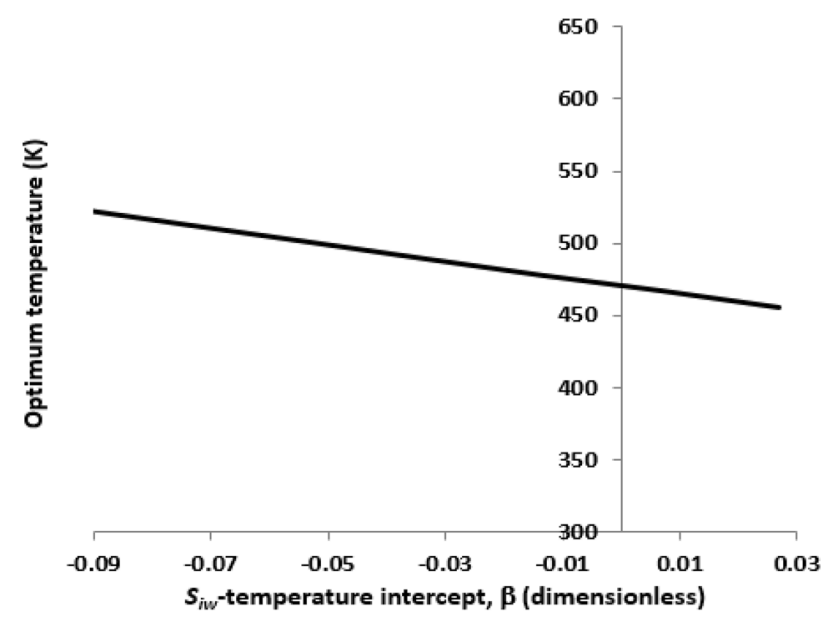

Fig. 5 Optimum operating temperature to maximize oil productivity and recovery as a function of the intercept of the $S_{i w} v s$. temperature function for an example steam flood $\left(a=0.002455 \mathrm{~K}^{-1}\right.$, $a=7000 \mathrm{~K}$ and $n_{0}=2.0$ )

model to investigate the existence of an optimum injection temperature for steam floods. As an example, a sector of the heavy-oil and bitumen belt in the Eastern Dahomey Basin, southwestern part of Nigeria is considered $[16,30]$.

A layer-cake stratigraphy is assumed with an 8-m oil shale unit sandwiched between two sand-rich units, each with a thickness of $15 \mathrm{~m}$. A uniform average porosity of $30 \%$ is considered while oil saturations are 68 and $80 \%$ in the oil shale and sandy units, respectively. The oil shale and sandy units are characterized by average horizontal permeabilities of 2000 and $400 \mathrm{mD}$ respectively, while all the units have a uniform vertical anisotropic ratio of 0.5
[16]. There is no initial free gas and aquifer. The reservoir is considered water-wet and hydrostatic, while relativepermeability functions are of Corey type. For completeness, the relative-permeability models account for temperature dependency. The reservoir model, characterized by a dimension of $200 \mathrm{~m} \times 500 \mathrm{~m} \times 38 \mathrm{~m}$, is described by a total of 7600 simulation cells (Fig. 6). While fine scale models are required for full-field simulation studies, relatively coarse layer-cake models are often suitable for preliminary screening of steam flooding projects, assessment of uncertainties as well as history-matching experimental and actual steam-injection projects [31, 32]. Each simulation cell is of dimension $40 \mathrm{~m} \times 12.5 \mathrm{~m} \times 1 \mathrm{~m}$.

To keep the problem simple and tractable, the fluid system is characterized by pseudo-components. These are a series of hypothetical close-cut fractions spliced from the boiling range distribution of crude oil fractions above carbon number 6 as a substitute to full compositional analysis. Its viscosity-temperature relationship is described with the two-parameter Andrade model (Eq. 1), assuming $\mu_{\mathrm{oi}}=7.0 \times 10^{-9}$ Pa.s. While mass and heat exchanges occur through the layers overlying and underlying the oil shale, there is neither heat nor mass transfer across the boundaries of the model. At model initialization, the stock-tank oil initially in-place (STOIIP) is $9.1 \times 10^{5} \mathrm{~m}^{3}$.

The well models and configurations follow a standard SAGD process. The model comprises two horizontal injector-producer pairs, placed some $100 \mathrm{~m}$ apart. As displayed on Fig. 6, the injectors are Inj1 and Inj2, while the corresponding producers are Prod 1 and Prod2. Each well has a completion length of $500 \mathrm{~m}$, radius of $0.16 \mathrm{~m}$ and perforated throughout their length. Both injectors and producers are characterized by a total skin factor of 5 , assumed constant throughout the simulation times. The producers are placed $2 \mathrm{~m}$ above the base of the reservoir while the injectors are $5 \mathrm{~m}$ above the producers. Saturated steam is injected at $70 \%$ quality, and all the wells have $100 \%$

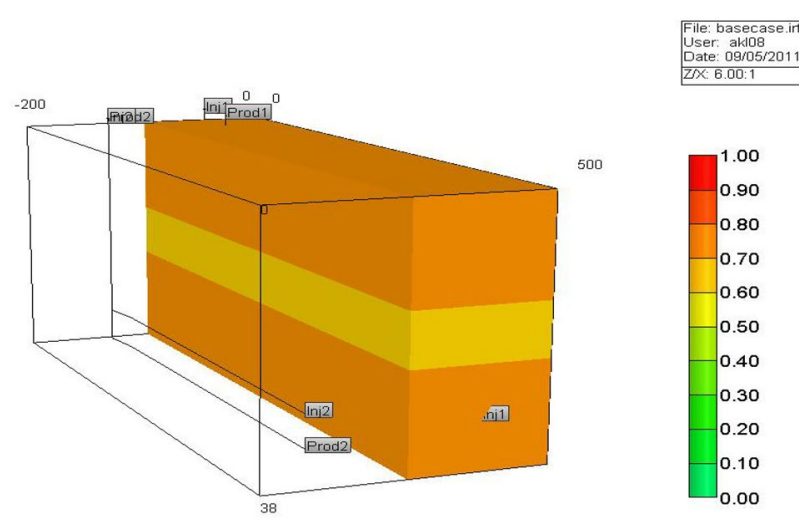

Fig. 6 A sector reservoir-simulation model showing SAGD well pairs and initial oil saturations 
Table 1 Some input data used in reservoir simulations

\begin{tabular}{|c|c|c|}
\hline Parameter & Value & Remark \\
\hline$a(\mathrm{~K})$ & 7000 & $\mu_{\mathrm{oi}}=7.0 \times 10^{-9}$ Pa.s \\
\hline$n_{0}$ & 2.0 & \multirow{4}{*}{$\begin{array}{l}7 \text { injection temperature }\left(T_{\text {inj }}\right) \text { cases are considered i.e. } 350,400,450 \text {, } \\
500,550,600 \text { and } 650 \mathrm{~K} \text {. For clarity, we maintained each injec- } \\
\text { tion temperature throughout the simulation case, as against the } \\
\text { optimization practice of gradually reducing injection temperature } \\
\text { during the wind-down phase or substituting steam with cheaper } \\
\text { thermal agents such as } \mathrm{CO}_{2} \text { and flue gas }[33,34] \text {. Use of these } \\
\text { input data in Eq. } 12 \text { suggests } 500.6 \mathrm{~K} \text { as the optimum temperature } \\
\text { for this example. This } T_{\text {opt }}<515 \mathrm{~K} \text {, falls within the optimum enve- } \\
\text { lope for total steam enthalpy (Fig. } 1 \text { ) }\end{array}$} \\
\hline$a\left(K^{-1}\right)$ & 0.002455 & \\
\hline$\beta$ & -0.05325 & \\
\hline$T_{o p t}(K)$ & 500.6 & \\
\hline
\end{tabular}

uptime in all cases. In the context of this study, some relevant parameters and their states are indicated in Table 1.

Liquid constraints of $250 \mathrm{~m}^{3} / \mathrm{D}$ are imposed on the production wells, while the injection wells have a coldwater equivalent (CWE) steaming rate of $280 \mathrm{~m}^{3} / \mathrm{D}$. By design, the steady-state voidage-replacement ratio is 1.1. Wellbore hydraulics are ignored. The producers and injectors are constrained to bottom-hole pressure (BHP) limits of 1000 and $4000 \mathrm{~Pa}$, respectively. Limiting production water cut is $90 \%$. In all simulation cases, geomechanical effects are ignored, and there is no provision for pre-heating of the reservoir. Initial reservoir temperature is fixed at $316 \mathrm{~K}$.

The optimization study is set up to achieve two main objectives. These are (i) maximize oil recovery; and (iii) minimize cumulative steam-oil ratio (CSOR), over a twenty-year injection and production period. To account for time effects occasioned by differences in productivity and injectivity due to varied injection temperatures, this study includes discounted oil recovery and CSOR. Annual discount rate is $10 \%$. In this work, discounted CSOR is simply the ratio of discounted oil recovery to the discounted cumulative volume of steam injected (in CWE). Therefore, as framed in this work, we seek the optimum operating temperature as that which best accomplishes all these objectives.

Oil recovery and CSOR as performance indicators: Considering absolute oil recovery and CSOR, performance plots for the production and injection wells are displayed in Figs. 7 and 8, respectively for various cases of constant injection temperatures in the range $350-650 \mathrm{~K}$. In all cases, the STOIIP is $9.0 \times 10^{5} \mathrm{sm}^{3}$. As would be expected, oil recovery increases over time, until a limiting state is reached. Compared to other injection conditions, no appreciable oil recovery is achieved in the case of steaming at $350 \mathrm{~K}$. This poor performance is attributed to the high viscosity ( $3400 \mathrm{mPa} . \mathrm{s})$ of in-situ oil at $350 \mathrm{~K}$. To put this in context, the corresponding in-situ oil viscosities at 400,450 and $550 \mathrm{~K}$ are approximately 280,40 and $2 \mathrm{mPa}$.s, respectively. On the other hand, there is no material difference in the recovery rates and ultimate recoveries within

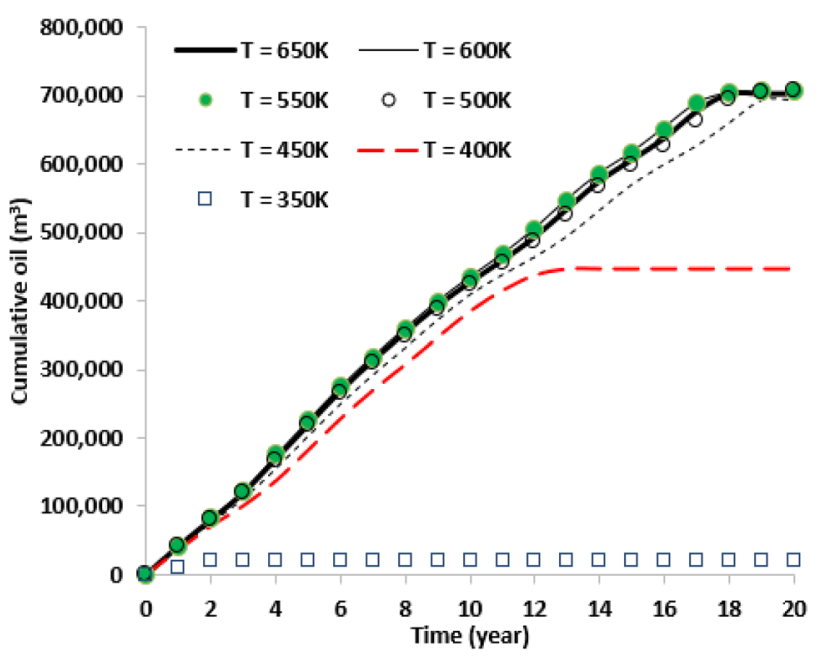

Fig. 7 Temporal variation of cumulative oil production for various steaming temperatures

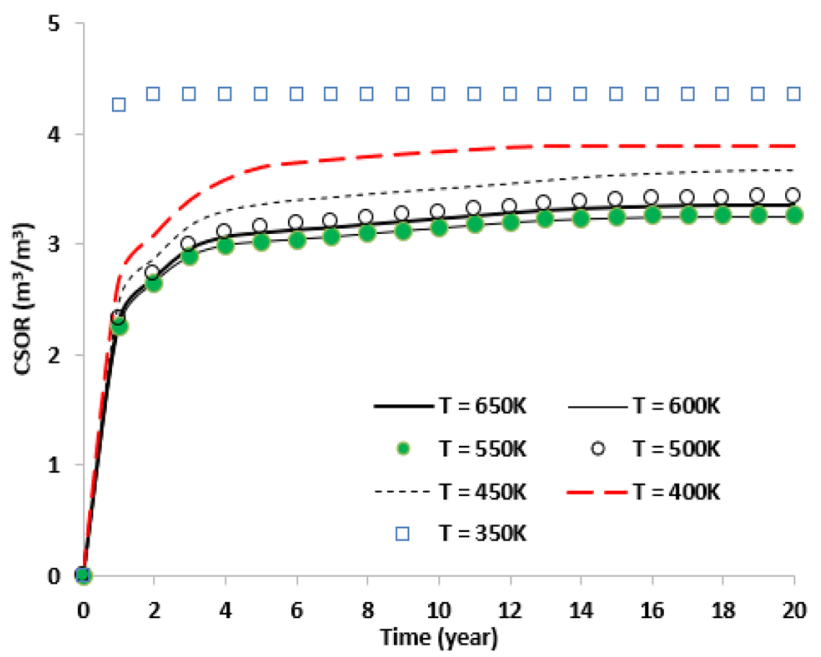

Fig. 8 Temporal variation of CSOR for various steaming temperatures 
the band 500-650 K. Clearly, viscosity effect is the main discriminator of the performances of the temperature band $350-450 \mathrm{~K}$ versus the range of higher injection temperatures in this example.

Similar to the deductions reached from Fig. 7 in terms of production rate and ultimate recovery (UR), Fig. 8 suggests that the same two broad categeories of performance can be observed in this example problem. Considering CSOR as a performance indicator, system dynamics exhibit clear sensitivity to temperature in the range $350-450 \mathrm{~K}$, but this sensitivity becomes negligible in the band $500-650 \mathrm{~K}$. Given that CSOR is a reaosnable indicator of energy and environmental performances, it follows that the optimum steaming temperature is in the interval $500-650 \mathrm{~K}$, within which energy and envonmental effciencies are maximized per unit volume of oil produced.

Effects of discounting: For better insights into the effects of time on the results, we present Figs. 9 and 10 as the absolute and discounted values of the performance measures, respectively. Fig. 8 shows that the upper limit of UR is essentially reached between 500 and $550 \mathrm{~K}$, while the same interval also yields the lower limit of CSOR. Beyond this temperature range, no significant increase in oil UR and reduction in CSOR are obtained in this example problem. It is interesting that the use of discounted UR and CSOR, as displayed in Fig. 10, substantiates the optimality of the temperature band $500-550 \mathrm{~K}$ in this example.

It is worthy of note that the current thermal simulations account for limited heat losses to the surrounding formations vis-à-vis the overburden and underburden. As a result, the adverse effects of higher injection temperatures such as 550, 600 and $650 \mathrm{~K}$ on CSOR are not fully quantified in these cases. As demonstrated by other workers, such thermal losses to the surrounding rocks in

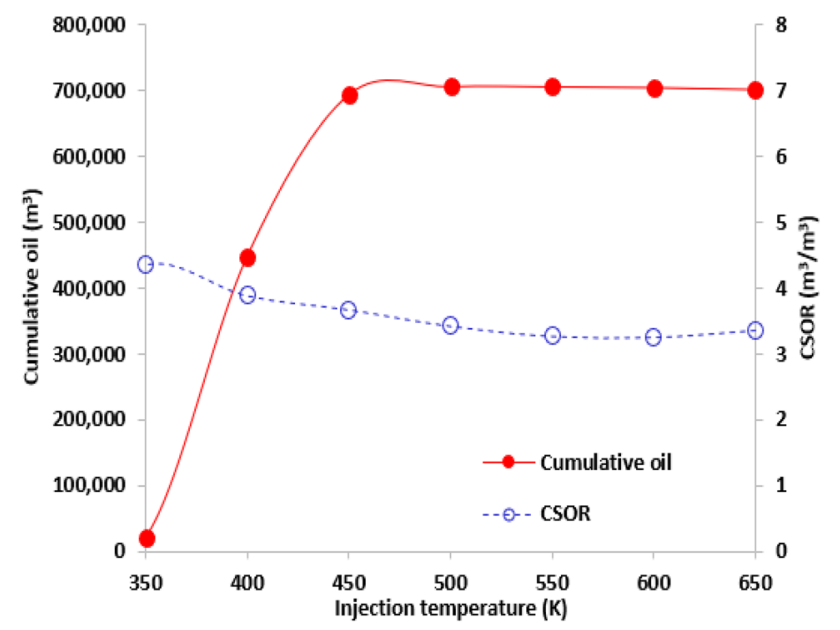

Fig. 9 Lifecycle absolute oil recovery and CSOR as functions of steaming temperature

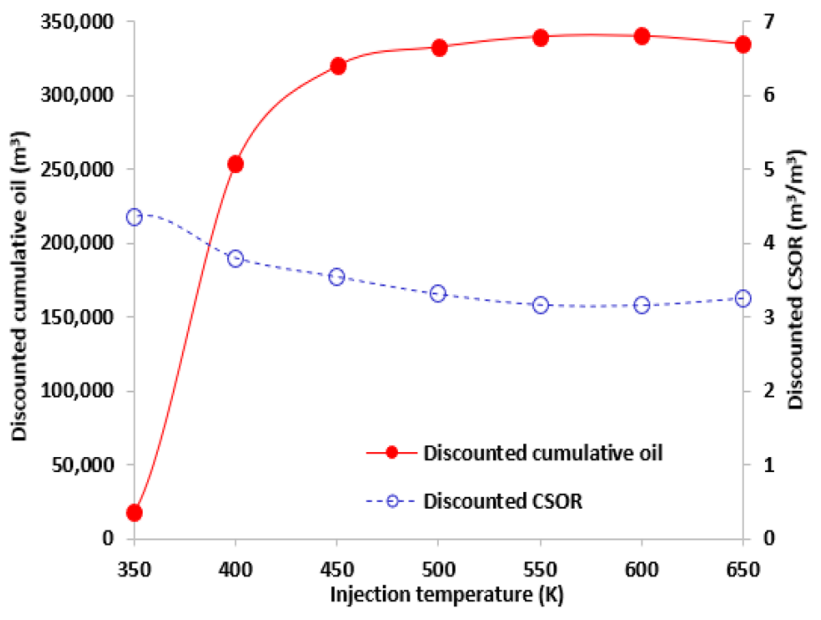

Fig. 10 Discounted lifecycle absolute oil recovery and CSOR as functions of steaming temperature

the reservoir as well as the enviornment in the course of steam transport along the injection network can be significant and detrimental to the performance of a steam flood. These losses constitute another disincentive to high-temperature steaming operations $[11,24,25,33]$. This argument underscores the $500-550 \mathrm{~K}$ band as optimum for this example problem.

In comparison, using the same set of input data for the example problem in our analytical model yields an optimum injection temperature of $500.6 \mathrm{~K}$ (Table 1). This estimate agrees with the optimum band $500-550 \mathrm{~K}$ obtained from detailed thermal simulations. Furthermore, this analytical model estimate is consistent with the theoretical maximum of $515 \mathrm{~K}$ obtained strictly from the standpoint of total enthalpy. Therefore, based on the results of the analytical model, thermal simulations and the upper limit of $515 \mathrm{~K}$ from total enthalpy, it is concluded that the optimum steam-injection temperature for the example case investigated is $\sim 501-515 \mathrm{~K}$.

Optimum operating temperature for productivity and thermal efficiency: The problem of determining the optimum operating temperature for a steam flood can be viewed from two broad perspectives. Based on the insights gained from this study, the two perspectives are related to the maximization of oil productivity and thermal efficiency (heat-transport capacity of steam). As shown in this study, the influence on thermal efficiency is generic because it is linked to total steam enthalpy, which is a universal property. In other words, providing the steaming temperature does not exceed $515 \mathrm{~K}$, the operating condition of a steam flood remains optimum from the standpoint of thermal efficiency. Because of the positive correlation between energy consumption and environmental impacts, it follows that the same optimum temperature $(<515 \mathrm{~K})$ is 
favourable to achieving favourable environmental efficiency. In this context, environmental performance should be viewed in relation to the amounts of water and fuel consumed to generate steam, $\mathrm{CO}_{2}$ emissions associated with steam generation as well as the amount of produced water handled per unit volume of oil produced.

Conversely, the optimum injection temperature required to maximize oil productivity is system specific. This optimum is controlled by the temperature characteristics of the rock and fluid properties, as described by the applicable relative-permeability and oil-viscosity models, respectively. Therefore, while the consideration of thermal (and environmental) efficiency yields $515 \mathrm{~K}$ as the upper limit of optimum operating temperature for a steam flood, the optimum range is further narrowed by the specific relative-permeability and oil-viscosity vs. temperature characteristics of the system of interest. While $515 \mathrm{~K}$ is the upper bound of optimum operating temperature for steam floods, the specific optimum operating condition would have to be evaluated on a case-by-case basis. This logical conclusion is an improvement over the positions advanced by Nguyen et al. [13] as well as Edmunds and Chhina [12], who recommended general optimum temperatures of 537 and $407-448 \mathrm{~K}$ for steam floods, respectively. We submit that such general recommendations by these previous workers do not appear to reflect the diverse and complex characteristics of the various heavy-oil and bitumen-bearing reservoirs, as well as the $515 \mathrm{~K}$ shown to be the universal upper limit to preserve the total enthalpy of saturated steam.

\section{Conclusion}

To aid the design and management of steam-flooding projects, a new semi-analytical model has been developed for conducting first-order estimation of the optimum temperature (pressure) at which oil productivity is maximized as a function of in-situ viscosity and relative permeability. Sensitivity tests suggest that it is sub-optimal to operate saturated-steam floods above $515 \mathrm{~K}$ (3.5 MPa).

As a robustness check, 3D multiphase thermal simulations were performed. Simulation results show that production rate, ultimate recovery and CSOR are sensitive to injection temperature in the range 350-450 K. However, for the cases examined in this work, these performance indicators do not exhibit strong dependency on injection temperature in the range $500-650 \mathrm{~K}$.

A close examination of discounted oil recovery and CSOR from the simulation runs reveals an optimum injection temperature band of 500-550 K, which compares reasonably well with the $\sim 501 \mathrm{~K}(<515 \mathrm{~K})$ from the new semianalytical model. It is noteworthy that these numerical and analytical results differ from the submissions of Nguyen et al. [13] as well as Edmunds and Chhina [12], who recommended general steam-flood optimum temperatures of 537 and $407-448 \mathrm{~K}$, respectively. For practical applications, we recommend that the optimum operating conditions of a steam flood should be treated on a case-by-case basis, while the proposed model is used for guidance.

From the standpoint of thermal efficiency, the operating temperature (pressure) of a saturated-steam flood should not exceed $515 \mathrm{~K}(3.5 \mathrm{MPa})$. Otherwise, there is a non-zero risk of sub-optimal steam flooding, owing to lower injected total enthalpy and higher thermal losses to the surroundings. Operating steamfloods at an optimum temperature $(<515 \mathrm{~K})$ is also favourable to the environment, as it offers maximum oil recovery while minimizing fuel costs, $\mathrm{CO}_{2}$ emissions as well as the net amounts of water consumed and produced per unit oil recovery.

One limitation of this study is that the new analytical model does not account for potential geomechanical effects. In addition, it is worthwhile to examine the optimum operating temperatures and pressures for non-saturated steam floods.

\section{Compliance with ethical standards}

Conflicts of interest The authors declare that they have no conflict of interest.

Availability of data and material All the data pertaining to this study are available upon request.

Open Access This article is licensed under a Creative Commons Attribution 4.0 International License, which permits use, sharing, adaptation, distribution and reproduction in any medium or format, as long as you give appropriate credit to the original author(s) and the source, provide a link to the Creative Commons licence, and indicate if changes were made. The images or other third party material in this article are included in the article's Creative Commons licence, unless indicated otherwise in a credit line to the material. If material is not included in the article's Creative Commons licence and your intended use is not permitted by statutory regulation or exceeds the permitted use, you will need to obtain permission directly from the copyright holder. To view a copy of this licence, visit http://creativecommons .org/licenses/by/4.0/.

\section{References}

1. Chan G, Reilly JM, Paltsev S, Henry Chen Y-H (2012) The Canadian oil sands industry under carbon constraints. Energy Policy 50:540-550

2. Meyer RF, Attanasi ED, Freeman PA (2007) Heavy oil and natural bitumen resources in geological basins of the world. https://doi. org/10.3133/ofr20071084 
3. Chen H, Wang Z, Wang K, Li Z, Li S (2020) Investigation of EOR mechanism for flue gas assisted SAGD. J. Pet. Sci. Eng. 193:107420

4. Prakash J, Sibaweihi N, Patel RG, Trivedi JJ (2020) “Data-driven steam optimization for SAGD". SPE paper 199908 presented at SPE Canada Heavy Oil Conference, Virtual, 29

5. Li S, Yu T, Li Z, Zhang K (2019) Experimental investigation of nitrogen-assisted SAGD in heavy-oil reservoirs: a two-dimensional visual analysis. Fuel 257:116013

6. Tian J, Liu H, Pang Z (2017) A study of scaling 3D experiment and analysis on feasibility of SAGD process in high pressure environment. J. Pet. Sci. Eng. 150:238-249

7. Huang $S$, Cao M, Cheng L (2018) Experimental study on the mechanism of enhanced oil recovery by multi-thermal fluid in offshore heavy oil. Int. J. Heat Mass Trans. 122:1074-1084

8. Crowley K, Wethe D (2019) "California bans high-pressure steam oil wells", Bloomberg, 19 November 2019

9. Al-Turki AA, Gates ID, Maini BB (2010) "On SAGD in oil sands reservoirs with no cap rock". SPE paper 137234 presented at Canadian Unconventional Resources and International Petroleum Conference, Calgary, 19-21 Oct

10. Gbadebo AM (2010) Environmental implications of bitumen seep induced pollution in parts of Ogun State, southwestern Nigeria. Environ. Earth Sci. 59:1507-1514

11. Roche P (2010). "Keep your cap on”, New Technology Magazine, May edition, 1-6

12. Edmunds N, Chhina $H$ (2001) Economic optimum operating pressure for SAGD projects in Alberta. J. Can. Pet. Tech. 40(12):13-17

13. Nguyen HX, Wisup B, Tran X, Ta DQ, Nguyen HD (2012) “Effects of reservoir parameters and operational design on the prediction of SAGD performance in Athabasca oilsands". SPE paper 154778 presented at SPE Europec/EAGE Annual Conference, Copenhagen, 4-7 Jun

14. Collins PM (2007) The false lucre of low-pressure SAGD. J. Can. Pet. Tech. 46(1):20-27

15. Collins PM (2007) Geomechanical effects on the SAGD Process. SPE Res. Eng. Eval. 10(4):367-375

16. Lawal KA (2011). Alternating injection of steam and $\mathrm{CO}_{2}$ for thermal recovery of heavy oil, $\mathrm{PhD}$ thesis, Imperial College London

17. Wei W, Gates ID (2010) "On the relationship between completion design, reservoir characteristics and steam conformance achieved in steam-based recovery processes such as SAGD". SPE paper 129694 presented at SPE Improved Oil Recovery Symposium, Oklahoma, 24-28 Apr

18. O'Dell PM (2012) "Optimum steam zone pressure". SPE paper 159157 presented at Annual Technical Conference and Exhibition, San Antonio, 8-10 Oct

19. Kam D, Park C, Min B, Kang JM (2013) An optimal operation strategy of injection pressures in solvent-aided thermal recovery for viscous oil in sedimentary reservoirs. Pet. Sci. Tech. 31(22):2378-2387
20. Arcelus-Arrillaga P, Pinilla JL, Hellgardt K, Millan M (2017) Application of water in hydrothermal conditions for upgrading heavy oils: a review. Energy Fuels 31(5):4571-4587

21. Liu J, Xing Y, Chen Y-X, Yuan P-Q, Cheng Z-M, Yuan W-K (2018) Visbreaking of heavy oil under supercritical water environment. Ind Eng. Chem. Res. 57(3):867-875

22. Reid RC, Prausnitz JM, Poling BE (1987) The properties of gases and liquids, 4th edn. McGraw-Hill, New York

23. Tortike WS, Farouq-Ali SM (1989) Saturated steam-property functional correlations for fully implicit thermal reservoir simulation. SPE Res. Eng. 4(4):471-474

24. Lawal KA (2020) Applicability of heat-exchanger theory to estimate heat losses to surrounding formations in a thermal flood. J. Petrol. Explor. Prod. Technol. 10:1565-1574

25. Valbuena E, Bashbush JL, Rincon A (2009) "Energy balance in steam injection projects: integrating surface-reservoir systems". SPE paper 121489 presented at the SPE Latin American \& Caribbean Petrolum Engineering Conference, Cartagena, 31 May-3 Jun

26. Doranehgard MH, Siavashi M (2018) The effect of temperature dependent relative permeability on heavy oil recovery during hot water injection process using streamline-based simulation. Appl. Thermal Eng. 129(25):106-116

27. Sedaee Sola BS, Rashidi F, Babadagli T (2007) Temperature effects on the heavy oil/water relative permeabilities of carbonate rocks. J. Pet. Sci. Eng. 59:27-42

28. Nakornthap K, Evans RD (1986) Temperature-dependent relative permeability and its effect on oil displacement by thermal methods. SPE Res. Eng. 1(3):230-242

29. Saeed MS (2010). Effect of temperature-dependent relative permeability functions on thermal recovery of heavy oil, MSc thesis, Imperial College London

30. Mosobalaje OO, Orodu OD, Ogbe D (2019) Descriptive statistics and probability distributions of volumetric parameters of a Nigerian heavy oil and bitumen. J. Petrol. Explor. Prod. Technol. 9(1):645-661

31. Tunnish A, Shirif E, Henni A (2019) History matching of experimental and CMG-STARS results. J. Petrol. Explor. Prod. Technol. 9:341-351

32. Miller KA, Xiao Y (2010) Lloydminster, Saskatchewan vertical well SAGD field test results. J. Can Pet. Tech. 49(1):22-29

33. Wang C, Liu P, Wang F, Atadurdyyev B, Ovluyagulyyev M (2018) Experimental study on effects of $\mathrm{CO}_{2}$ and improving oil recovery for $\mathrm{CO}_{2}$ assisted SAGD in super-heavy-oil reservoirs. J. Pet. Sci. Eng. 165:1073-1080

34. Lawal KA, Tendo $F$ (2015). "Steam-alternating- $\mathrm{CO}_{2}$ for heavy-oil recovery". SPE paper 178356 presented at SPE Nigeria Annual International Conference and Exhibition, Lagos, 4-6

Publisher's Note Springer Nature remains neutral with regard to jurisdictional claims in published maps and institutional affiliations. 